\title{
Research on the kiln site protection and utilization of early Yue in Zhejiang based on protection first
}

\author{
Shuang $\mathrm{Wu}^{1}$, Shou Lei $\mathrm{Gao}^{2 *}$ \\ ${ }^{1}$ School of History, Culture and Tourism, Guangxi Normal University, Guilin, 541001, China \\ ${ }^{2}$ Institute of Architecture and Environment Art, Shanghai Urban Construction Vocational College, Shanghai, 201415, China
}

\begin{abstract}
The architectural heritage of handcrafts of Zhenjiang has unrepeatable technological and historical values. This paper aims at obtaining a reliable overview of the occurrence of the kiln sites. Their characteristics and values as architectural heritage of handcrafts will be fully understanding, expounds the problems in the protection and utilization of those kiln sites, then gives different utilization strategies on the priority of the kiln site protection is put forward.
\end{abstract}

\section{Introduction}

Yue wares is one kind of high fired green glazed ceramics produced in Zhejiang, which is the most celebrated and typical examples of celadon in ancient China. For a long time, Yue wares held a leading position in the using market of $\mathrm{Ci}$ (瓷) wares in China before the white color wares was invented and popularity in northern of China. Broad speaking, the technique system of Yue wares production had maximum impact on the later ceramic production in China, especially the celadon production and used in southern area of China. Compare with the Yue wares of Sui and Tang dynasty, early period of Yue wares was not one of the heat research topics even among in Chinese scholars, because the lack of first hand of material and the discovered of kiln sites. Until 1975, celadon unearth from the burial of Fenghuabaidu[1] it proved that celadon manufacturing begun in Zhejiang as early as the late period of East Han dynasty.

This article aims to introduce the architectural remains of early period Yue wares production during $2^{\text {nd }}-6^{\text {th }}$ century $\mathrm{AD}$ in northern of Zhejiang, increasing the understanding of the distribution and its production. Firstly, this article can help to understand the production pattern of early period Yue wares and help determine other more specific questions about Yue wares and early time celadon production in China, about several 179 kiln sites are introduced by statistics and analysis. Secondly, analysis of early period Yue wares production technology can help elucidate the relationship between protoporcelain manufacture and the later times celadon, also other ceramic production among different regions. Thirdly, expounds the problems in the protection and utilization of those kiln sites, gives different strategies on the kiln site protection and utilization.

\section{The distribution of kiln sites}

The kilns site of celadon producing had been found in 1930s firstly, while all of them are regarded as a later time than $2^{\text {nd }}-6^{\text {th }}$ century AD. Not until the 1950 s, earlier period celadon producing kiln sites were found and confirmed, then, after three times cultural artifacts survey and many time investigations by archaeological institute of Zhejiang, now, about several 179 kiln sites can be confirmed of this period in Zhejiang. From 1990s, some of the kiln sites had been excavated for a further study, those fundamental work help built a map of the distributions and the status of celadon producing in ancient time. Table 1 shows the number, location and time period distribution of those kiln sites remain. Meanwhile, there are continuous production of kiln using between different time periods, here, the statistics number is based on the specific period, for example if one kiln site was used in both Three kingdom dynasty and West Jin Dynasty, it will be taking account in the total number of both two time periods.

Table1: The number of Kiln site in Zhejiang ( $2^{\text {nd }}-6^{\text {th }}$ century AD) EH: East Han dynasty; TK: Three Kingdom; WJ: West Jin Dynasty; EJ: East Jin Dynasty, N; Nan Dynasty.

\begin{tabular}{|c|c|c|c|c|c|}
\hline Location/Time period & EH & TK & WJ & EJ & N \\
\hline HuZhou & 5 & 3 & -- & 4 & 4 \\
\hline Shaoxing & 4 & 3 & 5 & 2 & 1 \\
\hline
\end{tabular}

*Corresponding author's e-mail: gaoshoulei@succ.edu.cn 


\begin{tabular}{|c|c|c|c|c|c|}
\hline Shangyu & 45 & 42 & 53 & 4 & 5 \\
\hline Cixi & 10 & 2 & -- & 6 & 4 \\
\hline Ningbo & 6 & 2 & 1 & -- & 1 \\
\hline Taizhou & 5 & 4 & 9 & 9 & 3 \\
\hline Yuyao & 1 & 3 & 6 & 2 & 1 \\
\hline Hangzhou & -- & -- & 1 & 5 & 1 \\
\hline Wenzhou & -- & -- & -- & -- & 1 \\
\hline Total & 76 & 59 & 75 & 32 & 21 \\
\hline
\end{tabular}

\subsection{Diachronic distribution}

Figure 1 shows the growing rule of kiln sites East Han Dynasty to Nan Dynasty. The diachronic distribution of kiln sites presents as a wave with obvious curve. However, according to the data, most of those kiln sites in East Han dynasty were not produced only one kind of ceramic, usually they produced earth ware, proto-porcelain, black glazed ware and celadon. since not all the kiln sites were excavated and published and the survey data made by different researchers, it is hard to distinguish clearly how many of the East Han dynasty period kiln site had been produce celadon only.This does not effect on the overall observation of changes in the number of kilns. Boarding

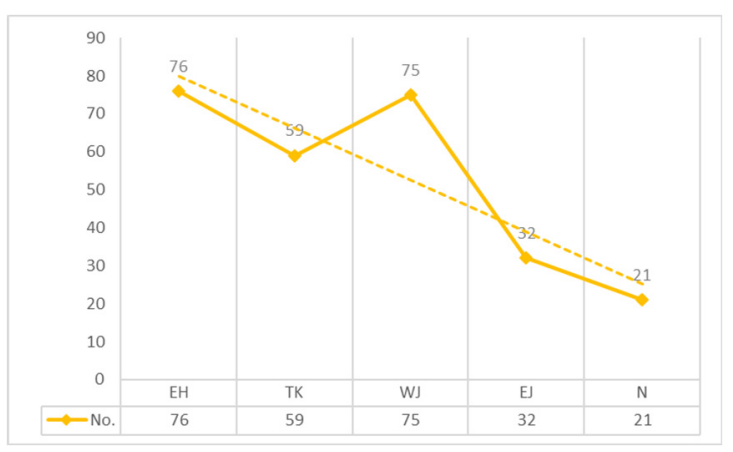

1.1 speaking, Qin and Han dynasty is a period of transition between earth ware and stoneware in China, pottery, protocol-porcelain, and celadon producing exist simultaneously[2]. Apart from the East Han dynasty, the products of the other periods kiln sites are celadon only. In Three kingdom period, there are two categories of kiln sites: one is evolved from East Han dynasty which turn from multiple products to celadon only; one is emerging during this period. Later West Jin dynasty is the peak time of celadon producing, achieve a maximum production capacity during $2^{\text {nd }}-6^{\text {th }}$ century AD. Since the beginning of the Eastern Jin dynasty the number of kiln sites fat twitch.

According to the figure 1, early time celadon manufacturing in Zhejiang had a clearly regular as original period-develop fast period-stagnation period.

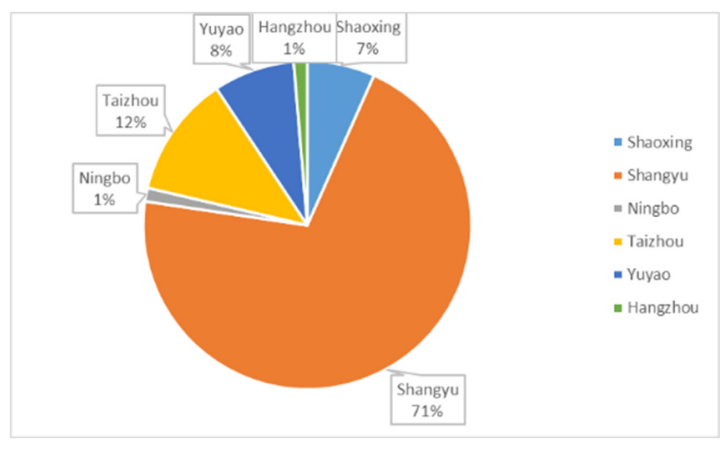

1.2

Figure 1: 1.1 The number of kiln sites found in different area and time period in Zhejiang, $2^{\text {nd }}-6^{\text {th }}$ century AD. 1.2 The number of kiln sites found in different area of West Jin period in Zhejiang, 2nd-6th century AD.

\subsection{Regional distribution}

Figure 1.2 shows the regional distribution of celadon producing kiln sites in different times. East Han dynasty, Shangyu had already keep $59 \%$ of the kilns site in Zhejiang. Later in Three kingdom and West Jin dynasty, after the mature celadon appeared, Shangyu keep a rate of $71 \%$. Relatively, other area in Zhejiang had a smaller and scattered distribution. During the East Jin dynasty, Shangyu lost the leader position in kiln sites distribution. Nan dynasty, even if the whole celadon manufacture were stagnation, Shangyu still had the biggest number of kiln sites.

\subsection{Remains in kiln site}

Although, the information that is contemporaneous with the early celadon manufacture remains is scare and not easy to interpret, but there are still many sherds and vessels from 2 th-6th century has been found by the work of archaeological investigation and excavation. Most of the celadon manufacture remains are found in the northeast of Zhejiang province, usually, those antiquities consist of kiln、workshop、 equipment and furniture. 

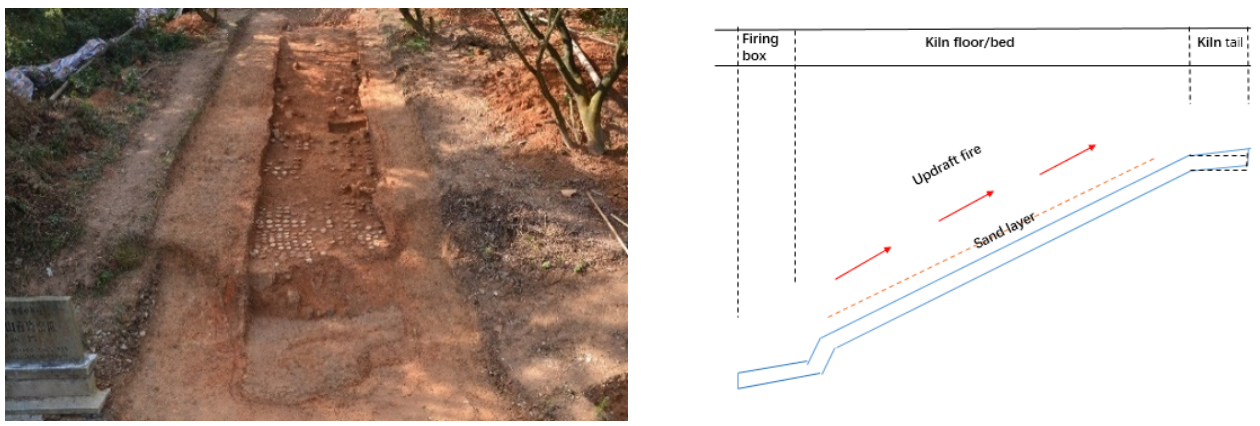

Figure 2: Dragon kiln found in Zhejiang and the image of its structure (by author).

\subsubsection{Dragon kiln}

Dragon kiln is one main kind of kiln pattern in ancient China, for now, more than half of the kiln sites unearthed in China are dragon kiln, most of them located in the lower reach of Yangtze river, particularly in Zhejiang, which located on the slop side of hill, with a rectangular of plane, on the ground[3]. Dragon kiln takes full use of the environmental resource, the style and location help updrafts the firing and adding the temperature, at the same time lie on the hill side make it convenient to get firing resource(wood) and avoid the destroy of water-flooded (drainage) Because the technological character of dragon, south of China, especially Zhejiang area, where with geological features as enough forest, water, clay and porcelain stone resources, became the perfect area for its using and development. At the same time, in a win-win situation, the raw material of celadon manufacturing in Zhejiang rich in Ferrum (Fe), which the key classical element of green color glaze making, the reducing flame and rapid cooling situation of dragon kiln is perfect to its formation[4].

Table 2 shows the information of dragon kiln in Shangyu during $2^{\text {nd }}-6^{\text {th }}$ century which the kiln building technology had stay stapled after a long-time exploration. In this period the length of kiln usually between $10-15 \mathrm{~m}$, the wide about $2-2.5 \mathrm{~m}$, but the technique of wood adding hole or open door at wall sides still not be innovated yet. Each time before firing, potter need to come into the kiln from the fire box which in the front of the kiln and the lowest stage of dragon kiln, then put the celadon wares depending on different size and temperature place. Broadly speaking, compare with the original pattern in early time, during East Han to Nan dynasty, (1) almost all the dragon kiln had consisted of three parts, firing box, kiln floor and tail. (2) The length is between 10-15m, longer than earlier period. (3) Furniture had been commonly used with different types and function for raising production number. (4) Most of the dragon kiln in this period can make use of chimney to keep a better temperature situation.

“- "instead for no detail data

Table 2: Data of kiln sites ( $2^{\text {nd }}-6^{\text {th }}$ century AD) found and excavated in Shangyu

\begin{tabular}{|c|c|c|c|c|c|c|c|c|c|c|c|}
\hline Name & Time & Length (m) & & & & wide $(\mathrm{m})$ & Slope $\left(^{\circ}\right)$ & & & & chimney \\
\hline & & Total & firebox & floor & tail & & total & Fire box & floor & tail & \\
\hline DayuanpinY1 & EH & $>10 \mathrm{~m}$ & About 1.5 & - & - & 2.2 & $20^{\circ}$ & - & - & - & - \\
\hline & & & & & & & & & & & \\
\hline Xiaoluao Y1 & EH & - & - & - & - & - & 20 & - & - & - & exist \\
\hline ZhangzishanY1 & EH & 3 & - & - & - & - & - & - & 28 & 21 & exist \\
\hline ZhangzishanY & EH & - & - & - & - & $1.97-2.08$ & - & - & 31 & 14 & - \\
\hline Anshan & TK & 13 & about0.8 & - & - & $2.1-2.4$ & - & 13 & 23 & 5 & exist \\
\hline NigupoY1 & TK-WJ & 13 & 1.7 & - & - & 2.2 & - & 12 & 22 & & exist \\
\hline & & & & & & & & & & & \\
\hline Zhangzishan & WJ-EJ & - & - & - & - & 2.4 & - & - & 10 & $<10$ & exist \\
\hline & & & & & & & & & & & \\
\hline
\end{tabular}

\subsubsection{Workshop, celadon sherds, and furniture}

So far, few workshops remain unearthed, on the one hand, Zhejiang area has been economical center for thousands of years, they may be destroyed, on the other hand, at the early time the handcraft may be happened inside house instead of gathering manufacture. Compare with the kilns, there are few remains of workshop and equipment for clay handling, and forming.
Another most important kind of remains are the product sherds in the kiln sites[5]. They usually discard with furniture and keep a huge number. Most of those sherds were failed firing, broken or with flaw. Their shape and forms can cover all the products of one kiln sites.

Just as the dragon kiln, furniture is also one feature of celadon manufacture system in ancient Zhejiang. Furniture is one kind of equipment of celadon producing, which usually make of local clay material, instead of unique/single form, their size and shapes are multiplicity and match with the different style of celadon ware. 
Furniture did not innovate and used widely until East Han dynasty. As one of the most important technology innovation of ceramic production, the raw material of furniture is easy to get with low cost, but the appear and use of them add a big number of products output and successful rate.

Based on their function this chapter divide furniture remains them into three main kinds: supporting furniture, propping furniture and spacing furniture. (figure 3 )

(1) Spacing furniture: usually put between the celadon wares for make full use of space and adding output number of celadon products and reducing the breakage rate.

(2) Propping furniture: usually put between the supporting furniture and the lowest level celadon ware, play a stabilizing role, so their shape and size were decided by the bottom shape of the lowest level ware.

(3) Supporting furniture: usually put on the sand layer which on the kiln floor directly for support the celadon ware in a better firing situation and avoid destroyed by the sand layer; their size changing with the firing temperature, because the fire in dragon kiln is up draft so regularly the supporting furniture which in front is lower than middle and late stage.

It should be noticed that the most of the furniture cannot play a single function, especially the propping furniture and spacing furniture, both can hold the three kinds of function, it depends on different using situation.

Moreover, the material of furniture also effected by their specific function. For increasing the quality and decreasing the breakage rate as much as possible, during this period potter had begun made furniture by different material intentionally. Usually, the spacing furniture are made of porcelain stone but the other kinds furniture which don not touch the celadon product directly are still made by clay.
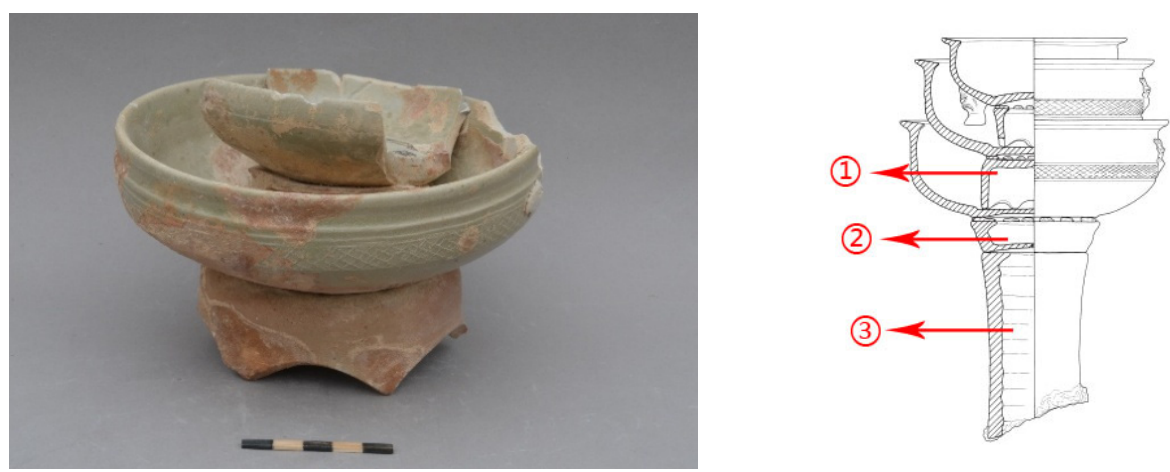

Figure 3: Photos and image of three kind of furniture. (photos offered by Zheng Jianming)

\section{Characteristic and value of the kiln site of early Yue in Zhejiang as architectural heritage of handcrafts}

For about 1300 years, celadon was the most famous stoneware in south of China, holding the most advanced celadon producing technique. From the Tang dynasty, people like to use "green glazed ware in South but white glazed ware in North" to describe the stoneware manufacture situation in China. However, the technique of celadon producing in Zhejiang origin earlier and more had a big area effect on other area of China, even the Japan and Korea. The technique system of celadon producing as dragon kiln, furniture and green color glaze had been completed during this period, later then the Yue wares producing in Sui and Tang dynasty and the Longquan ware producing from Song dynasty were take this model as the technique fundament. Furthermore, the technique also has affected on the ceramic producing in others area in China and outside China.

It has been proved that dragon kiln was made of clay and organic material as the main body, there were a sand layer on the floor when firing for stabling the celadon and protect wares from fire directly. In the excavation work of Qianshan kiln, there are bamboo trail on the clay-making wall of kiln. Therefore, Wang and Shen suppose that the roof of dragon kiln was take bamboo as body then covered by wet clay. In other words, the kiln sites of early Yue are one kind of material heritage of handcraft; it shows the origin and development of celadon making history of China. Furthermore, it is also architectural heritage of handcrafts.

\section{Thinking about the current situation of the kiln site and the protection and utilization strategies}

\subsection{The protection and utilization strategies}

\subsubsection{Based on the protection first}

Material heritage is non-renewable resource and the supporter of our civilization. However, many of those kiln sites in Zhejiang are under the threat of erosion by changing land use. As mentioned before, Shangyu is an important production center of early celadon handcraft, firstly, all the protection and utilization actions should base on the protection first. For example, we can build a site museum on the site or around the site, protect the kiln site through the exhibition, education and serve function of museum[6]. Second, kiln site need professional repair and protection, here, we should depend on the professional management agency, they will use a combination of techniques to make actions. Thirdly, more time survey 
projects needed for obtaining a reliable overview of the occurrence of early Yue kiln sites.

\subsection{2 let public know what it is!}

Both public archaeology and the professional management agency, like to emphasize the important position of citizen during the protection and utilization actions. Human being are the creator, the owner and the protector of material heritage let them know the characteristics and the value of those kiln sites for better protection, also, help elaborate protection measures in negotiation with land owner.

\subsubsection{Reuse it!}

Reuse is one of the most effective form of protection. Except the form of site museum, culture and art center is also a good way to activate that architectural heritage of handcrafts. Taoxichuan in Jingdezhen city will a successful case.

\section{Conclusion}

Shangyu is the celadon production center of early Yue during $2^{\text {nd }}-6^{\text {th }}$ century. There are obvious regularity in the distribution and migration of kiln sites in each stage and the interaction characteristics of kiln site. In addition, clarifying the distribution characteristics the kiln remains can also help us to carry out the protection activities effectively.

\section{Acknowledgments}

This paper supported by the 2020 Guangxi Planning office of Philosophy and Social Science project 20BKG001 funded and 2020 Development Institute of ZhujiangXijiang Economic Zone project ZK2020003 and the firstclass higher vocational (professional) construction project "first-class professional construction of cultural relics restoration and conservation" (project number: YZ-2019A) funded,

\section{Reference}

1. Wang, LH. Lin, SM.(1981)The report of Fenghuabaidu tomb in 175AD. Journal of the Zhejiang Provincial Institute of Archaeology. Beijing: Cultural relics Press, 208-211.

2. The Chinese ceramic society. (1982)History of ceramic in China, Beijing: Cultural relics Press, 127.

3. Xiong HT. ( 1995)Research on the development and transition history of kiln technology in East Asia, Nanjing: Nanjing University Press, 83 .

4. Wood, N. (1999) Chinese Glaze: Their Origins, Chemistry and Recreation. London: A\&C Black Publishers Ltd. 35.

5. C.A. Pool. Why a kiln? Firing technology in the sierra de los Tuxtlas, Veracruz (Mexico)[J], Archaeometry
42, I(2000),61-76.

6. Philip Verhagen., Michiel Gazenbeek. The use of predictive modelling for guiding the archaeological survey of Roman pottery kilns in the Argonne Region (Northeastern France) [A], in Mark W. Mehrer, Konnie L. Weascott(Ed.) GIS and archaeological site location modelling[M], Philadelphia: Taylor \& Francis Group,2006:447-460. 